It will be evident that thermal diffusion represents a most valuable new tool at the disposal of the chemist, facilitating separations of a most diverse character. One practical point that has already come up for investigation is the influence of thermal diffusion on ingot segregation in steels. Metals are such good conductors of heat that it seems unlikely that any steep temperature gradient could persist for a sufficient length of time in the liquid contained in an ingot mould for thermal diffusion to induce significant segregation. At the suggestion of $\mathrm{Dr}$. C. H. Desch, however, an experiment to test this point was undertaken in my department by Dr. Ritchie. The apparatus employed was similar to that already described, but the annular distance was reduced to $0.25 \mathrm{~mm}$. and the length of the concentric tubes increased to 2 metres. The annular space was filled with a solution of 1.5 per cent zinc (density $7 \cdot 1$ ) in mercury (density $13 \cdot 6$ ). Even under such favourable conditions, no fractionation whatever was observable after a run lasting for 32 hours.

This negative result is no doubt largely due to the high thermal conductivity of the amalgam, which reduces the temperature gradient by making the drop between the annular liquid surfaces much less than that between the surrounding glass walls. The same factor, however, as has been noted above, should also diminish the effect of thermal diffusion in ingots. Further work in the field is obviously necessary, but in the meantime the view expressed by Desch that thermal diffusion cannot play an appreciable part in producing the observed segregation in steel ingots appears to be fully justified.

\section{FUTURE OF THE POPULATION OF GREAT BRITAIN}

\section{BY COLONEL SIR CHARLES ARDEN-CLOSE, K.B.E., C.B., C.M.G., F.R.S.}

A N interesting memorandum, entitled "Current A Trend of Population in Great Britain", was presented to Parliament by the Minister of Health and the Secretary of State for Scotland in May 1942*, but it is explained, in the opening paragraph, that this memorandum was actually "submitted shortly before the outbreak of the war by the RegistrarsGeneral of England and Wales and of Scotland to the Royal Commission on the Geographical Distribution of the Industrial Population". It was not included in the papers published by that Commission. The facts dealt with are those available up to April 1938 and no account is taken of the War.

The memorandum is in the form of a compact little pamphlet of twelve pages, with tables and two diagrams. The account is somewhat compressed and requires attentive study. It brings our knowledge of the facts reasonably well up to the date mentioned, and, with the aid of certain assumptions, gives indications of what our numbers might be twenty or thirty years hence; but it has to be borne in mind that the assumptions do not include the possibility of war.

The main intention of the memorandum is stated to be the presentation of the facts in as objective a manner as possible, so as to correct misunderstandings based on rather sensational forecasts as to

* H.M. Stationery Office, 1942. 2d. net. what might be the fate of the population of Great Britain a century or so hence. A warning is given that forecasts extending to such a distant future have very slight value.

It is stated that, "as long ago as 1926, attention began to be drawn in official reports to the significance of the phase which the falling birth-rate was then entering". The crude birth-rate, which reached its maximum of $\mathbf{3 5 . 4}$ per thousand of the population in the period 1871-75, after that showed a continuous decline until the year 1933 when it reached the low figure of 14.7, "from which time the fall appears to have been arrested and a minute, though so far uninterrupted, reverse of the movement taken its place". The estimated figure given for 1938 was $15 \cdot 5$, but actually it was $15 \cdot 1$. We can bring the figures up to date, thus : $1939,14 \cdot 9 ; 1940,14 \cdot 6 ; 1941,14 \cdot 2$. These figures are later than the date of preparation of the pamphlet; they are obviously affected by the War and will not serve as a guide to future peace-time rates, for it must be remembered that great wars, such as the War of 1914-18, or the present War, do materially diminish the populations of the countries engaged in them ; the population of Great Britain was probably some two millions less at the time of the census of 1921 than it would have been had there been no war a few years before.

A table is given to show the average annual percentage of increase of our population, and from this it appears that between 1871 and 1911 the average annual increase was $1 \cdot 12$, but after 1911 there was a marked drop and the average increase up to 1938 was about $0 \cdot 45$. The most striking drop was from 0.98 in $1901-11$ to 0.46 in $1911-21$, that is, the most marked change occurred in the war period "when the rate of increase, which, prior to that time had been of the order of 1 per cent per annum, dropped to rather less than half that figure, at which level it has been maintained ever since".

It is well known that since 1923 the birth-rate has not been sufficient to provide a stationary population ; in fact the births are only, by Dr. Kuczynski's calculation, about three quarters of the number required to reach that standard, in spite of the present continued increase of our numbers. Later information puts the net reproduction-rate, in 1938, as 0.84 , so that fertility would have had to be raised by about one fifth to result in a stable population. To illustrate the "transitory and unbalanced nature of the present age distribution" a comparison is made between this and two theoretical stationary populations, resulting in each case from a constant annual number of births of 700,000 , with different rates of mortality. It is stated that the comparisons show that the population would be maintained at or near its present level of forty-six millions if there were continued the flow of 700,000 births which were registered in 1937. But, of course, the supposition of a continued, constant flow of this kind "could only be realized by a gradual rise in fertility over the next two or three decades". It is added that such a recovery might possibly be secured "with the aid of measures ensuring a national population policy".

The male section of the important group $15-45$ is now much smaller than the female section of that group. It is possible that this inequality is not sufficiently stressed by demographers. The marriagerate must be adversely affected by such a disparity. We all of us know of women who have lost their prospective husbands in the War of 1914-18, and of others who found themselves in a world which 
contained too few marriageable men If we think only of the number of marriageable women we shall be apt to forget the question of whom they are to marry. The Registrar-General for England and Wales reported in 1940 that there were more than a million and a half surplus women of marriageable age in the middle of 1939. The present War is not going to make this state of things any better.

An important consideration, too often neglected, is brought forward with regard to mortality. Too often it is assumed that the death-rates at the different ages have improved so much during the past two generations that further significant improvement is unlikely. Here we have clear indications to the contrary. A couple of diagrams are printed which show, in graphic form, the improvement in the deathrates of males and females, not only in the early stages of life, but up to, and including, the decade 75 to 85 in fact, practically for the whole of the normal life of man. In the construction of the diagrams the "death rates experienced in Great Britain over successive decennial periods between 1861 and 1931" are recorded for a series of age groups from 10 to 85 . The general character of the curves so obtained is the same for all groups-all show an improvement. The curves have been extended by dotted, free-hand lines, which may be taken to show the probable death-rates at the various ages for the next thirty years. The ordinates (death-rates) are plotted on a logarithmic scale.

The authors are satisfied that this simple way of predicting the future is justified by consideration of statistical continuity, of the effect of curative medicine, and of the fact that some other countries have mortalities lower than Great Britain. It is noteworthy that the Registrars-General should have directed attention to the improvement in British mortality. There has been too much silence on this point on the part of unofficial persons and bodies who have, in recent years, studied the question of the future of our population. The Registrars-General remark that they "find no justification for the assumption, implied in some of the contemporary population forecasts ... that the most probable course of mortality is one which shows no significant improvement on the rates actually experienced in recent years".

So much for mortality; and now for fertility. The line taken is that there was no diminution of the crude birth-rate in Great Britain after the low level $(14 \cdot 7)$ of 1933 ; that there was, in fact, a slight improvement. The values for the five years 1934-38 were $15 \cdot 1,15 \cdot 1,15 \cdot 2,15 \cdot 2,15 \cdot 1$. (The figure for 1938 was not actually available when the report was written, and an approximate value of 15.5 was given.) The pamphlet directs attention to the steadiness of the rate during these years, and it is remarked that "it would be unwise and unjustified to assume that any future departure from the present level is more likely to be in one direction than the other". It may here be noted that the Population Investigation Committee, in its publication "The Future of our Population", issued in 1936, put the average crude birth-rate in England and Wales as likely to be 12.4 for the five years $1935-39$. This has proved to be wide of the mark.

As for the years $1939,1940,1941$, the crude rates were $14 \cdot 9,14 \cdot 6,14 \cdot 2$; but these are war years and the only proper inference is that a world war has a disturbing effect on the birth-rate; this, indeed, is only common sense. The Registrars-General, then, make use of a constant fertility rate. The table on p. 9 of the pamphlet, which shows the effect of applying this rate, is somewhat difficult to follow, but we can accept the statement that the birth-rates were calculated with no bias in one direction or the other. Of course the calculations were made before the outbreak of the War and give no guidance for the war period, which may be a long one.

Since the pamphlet was published there has become available further information, based upon the data provided in accordance with the Population (Statistics) Act of 1938. From this it appears that married fertility has declined since 1921, at all ages of the mothers, decreasing to about two thirds of its previous value at $40-44$; and the rate of childbearing has decreased with the interval since marriage. This change is only explicable by deliberate family limitation.

The final factor dealt with is migration. It is assumed that, since the net outward migration from Great Britain for the years $1924-30$ was 1.2 per thousand of the population, and the net inward migration for the years 1931--37 was $1 \cdot 4$ per thousand, that this inward migration would continue "up to 1941, followed by a gradual reduction to vanishing point in 1951, and nil thereafter". This forecast is now, owing to the War, valueless.

With these three factors, mortality, fertility and migration, thus determined, the authors proceed to gather up the results so far as concerns the numerical future of our population. They say that in their calculation there has been no conscious bias in either direction. There is, of course, a margin of uncertainty in the assumptions, and this uncertainty must render distant forecasts increasingly unreliable. But they make allowances for favourable and unfavourable variations in the basic assumptions, and give the effect of $a \pm 10$ per cent variation in the ultimate mortality and fertility to be reached in 1971, with proportionate differences in the intervening years. No variation is made with regard to migration. It is added that the forecasts "make no allowance whatever for such change as might ensue from the possible introduction of a controlled population policy in regard either to the birth rate or to migration".

Here are some of the final results :

Total Poptlation of Grat Britain (thousands)

\begin{tabular}{|c|c|c|c|c|}
\hline $\begin{array}{c}\text { Actual population } \\
1937\end{array}$ & 1941 & 1951 & 1961 & 1971 \\
\hline 46,008 & $\begin{array}{r}46,565 \\
\pm 25\end{array}$ & $\begin{array}{c}47,501 \\
\pm 280\end{array}$ & $\begin{array}{r}47,192 \\
\pm 805\end{array}$ & $\begin{array}{r}45,980 \\
\pm 1,579\end{array}$ \\
\hline
\end{tabular}

Taking the lowest figure, we might, but for the War, have expected a population in 1971 of about $44 \frac{1}{2}$ millions, in place of the 1937 population of 46 millions. What is a matter of some concern is the age distribution which is shown in the same table. We see that in 1971 , according to these calculations, the number of children under fifteen will have come down from 10 millions to $7 \frac{1}{2}$ millions; the numbers in the working ages $15-45$ will have been reduced from $21 \frac{1}{2}$ millions to a little over 17 millions; and the category "over 65" will have increased from 3.9 millions to 7.9 millions. These are the troublesome features of a birth-rate which is insufficient, ultimately, to provide a stationary population. The mere reduction of total numbers might have certain advantages in such a very densely 
populated country as England. But the overloading of the country with people past work, or, at any rate, not equal to exerting the energy expected of the middle-aged, has no advantage at all.

These calculations would give a date for the attainment of the maximum population some time between 1951 and 1961. An unofficial estimate made in 1927 gave the year of the maximum as betwoen 1949 and 1953. Dr. Enid Charles's estimates, published in 1935, based upon three different assumptions, and very carefully worked out, gave the year of the maximum as 1940,1944 or 1960 . All that we can say is that the maximum has not yet (1942) been reached, and that all estimates have been upset by the War.

We cannot tell how long the War will last, or how many of our young and middle-aged men will be killed or permanently disabled. But we do know that there is the certainty of the War's disturbing effect on the birth-rate, which has already dropped from the recent pre-war average of $15 \cdot 1$ to $14 \cdot 2$ in 1941. Moreover, war takes its chief toll from the young men, and the result must be that the disparity between the numbers of males and females will be still further accentuated, as also will be the ageing of the population as a whole.

To take a long view then, it would appear that, while we need fear no serious diminution of our numbers for the next generation, the population will grow steadily older, and if we wish eventually to attain a happy condition of equilibrium, with a satisfactory age distribution, and thus avoid dangerous decreases of population in the times of our grandchildren and great-grandchildren, we should take steps as a nation, now, to encourage an improvement in the birth-rate.

\section{THE HUMAN FACTOR IN PRODUCTION*}

\author{
By DR. MAY SMITH \\ Industrial Health Research Board
}

$\mathrm{T}$

HE word 'production', like its fellow 'output', is an uninspiring word. Those of us who must use it for convenience need to remind ourselves at intervals that it is a general term and really stands for concrete things. Behind each article is an innumerable company of human beings, each with his hopes and fears, dreams and realities. This may be a machine age; industry may be mechanized, but personally I have never met the mechanized human being.

The work of any human being, like any other activity, can be affected positively or negatively by numerous causes, and a complicated web has to be unwoven if these causes are to be sorted out. Nor are all of them equally operative all the time; now one, now the other is thrown into relief with the others in the background.

Output is affected by the material and the psychological environments and by the physical and mental make-up of the individual.

- Substance of a paper read on June 6 before a conference on "Social Biology in Relation to the War" arranged by the British Social
Hygiene Council.

\section{Factors in the Material Environment}

(a) Lighting. Natural lighting (daylight) is ideal when there is plenty of it. Since it is not available for night work, and for the ordinary hours of work in winter, and since the black-out has interfered still further, a satisfactory substitute has to be found. With inadequate illumination, output is reduced by a slower rate of working and by an increase of spoilt work. The liability to experience eye strain, 'nervous trouble' (probably irritability) and accidents is increased.

(b) Heating. Lack of warmth on one hand, and overheating on the other, cause discomfort. Experience gained during the War of 1914-18, and by investigations made since, has shown that efficiency falls when the temperature rises unduly-particularly in heavy industries. In industries such as iron and steel, tin plate and glass manufacture, output is lowest in the hot summer months and highest in the winter. Even in the lighter work of textile operatives, the work deteriorates as the temperature rises above the comfort zone. On the other hand, low temperatures adversely affect manual dexterity. Broadly speaking, those atmospheric conditions which are generally found to be comfortable are also those which are best from the point of view of efficiency and safety.

(c) Ventilation. The first requirement is an ade. quate supply of chemically pure fresh air. After that, attention has to be paid to the temperature, humidity and rate of movement of the air. War-time lighting restrictions interfere considerably with ventilation arrangements. When a night shift is worked, arrangements for securing adequate ventilation are even more imperative. The problem of obtaining this adequate ventilation is not a purely mechanical one; there is also a psychological factor.

(d) Hours. Within limits, an increase of hours will increase the output. The human being is not a machine, and this being so, he can by force of will drive himself to perform far more than he considered his maximum. There were endless examples of this in industry after the Dunkirk period. To do this. however, reserve energy has been used; he has as it were used his reserve energy; and such activity can only be carried on for a limited time, after which considerable reduction occurs. The result is that after a continuous period of overwork, improvement in output does not take place for a considerable time after the return to normal hours. The Health of Munition Workers' Committee of the 1914-18 War summed up thus: "Misguided efforts to stimulate workers to feverish activity in the supposed interests of output are as useless as would be the cheers of partisans encouraging a long distance runner to a futile sprint early in the race."

Even with normal hours of work, the long spells of four and a half or five hours should be broken up preferably by organized rest pauses and not by acci dental interruptions due to waiting for materials, etc. Most people can face with equanimity work of about two hours' duration and can keep a steady pace, but the prospect of five hours' unbroken work often exerts a retarding influence on speed. The effect of any continuous activity, whether physical or mental, is associated with a gradually diminishing success in that activity. The stages at which full success is replaced by partial success and eventually by failure are not the same for everyone, or constant for the same person. Anything that reduces the 